\title{
Personalisation of Learning in Virtual Learning Environments
}

Citation for published version (APA):

Verpoorten, D., Glahn, C., Kravcik, M., Ternier, S., \& Specht, M. (2009). Personalisation of Learning in Virtual Learning Environments. In U. Cress, V. Dimitrova, \& M. Specht (Eds.), Learning in the Synergy of Multiple Disciplines: 4th European Conference on Technology Enhanced Learning, EC-TEL 2009 Nice, France, September 29-October 2, 2009 Proceedings (Vol. 5794, pp. 52-66). Springer-Verlag Berlin Heidelberg. https://doi.org/10.1007/978-3-642-04636-0_7

\section{DOI:}

10.1007/978-3-642-04636-0_7

Document status and date:

Published: 01/01/2009

Document Version:

Peer reviewed version

\section{Document license:}

CC BY-NC-ND

Please check the document version of this publication:

- A submitted manuscript is the version of the article upon submission and before peer-review. There can be important differences between the submitted version and the official published version of record. People interested in the research are advised to contact the author for the final version of the publication, or visit the DOI to the publisher's website.

- The final author version and the galley proof are versions of the publication after peer review.

- The final published version features the final layout of the paper including the volume, issue and page numbers.

Link to publication

\section{General rights}

Copyright and moral rights for the publications made accessible in the public portal are retained by the authors and/or other copyright owners and it is a condition of accessing publications that users recognise and abide by the legal requirements associated with these rights.

- Users may download and print one copy of any publication from the public portal for the purpose of private study or research.

- You may not further distribute the material or use it for any profit-making activity or commercial gain

- You may freely distribute the URL identifying the publication in the public portal.

If the publication is distributed under the terms of Article $25 f a$ of the Dutch Copyright Act, indicated by the "Taverne" license above, please follow below link for the End User Agreement:

https://www.ou.nl/taverne-agreement

Take down policy

If you believe that this document breaches copyright please contact us at:

pure-support@ou.nl

providing details and we will investigate your claim.

Downloaded from https://research.ou.nl/ on date: 26 Apr. 2023 


\title{
Personalisation of Learning in Virtual Learning Environments
}

\author{
Dominique Verpoorten, Christian Glahn, Milos Kravcik, Stefaan Ternier and \\ Marcus Specht \\ CELSTEC, Open University of the Netherlands, Valkenburger Weg 177, 6411AT Heerlen, \\ The Netherlands \\ \{dve, cgl, mkv, str, spe\}@ou.nl
}

\begin{abstract}
Personalization of learning has become a prominent issue in the educational field, at various levels. This article elaborates a different view on personalisation than what usually occurs in this area. Its baseline is that personalisation occurs when learning turns out to become personal in the learner's mind. Through a literature survey, we analyze constitutive dimensions of this inner sense of personalisation. Here, we devote special attention to confronting learners with tracked information. Making their personal interaction footprints visible contrasts with the back-office usage of this data by researchers, instructors or adaptive systems. We contribute a prototype designed for the Moodle platform according to the conceptual approach presented here.
\end{abstract}

Keywords: Personalisation, self-regulation, VLE, learner support, learner tracking

\section{Introduction}

Good pedagogy is commonly assumed to be related to individualized learning. This perspective sees learners as separate entities with unique learning goals and needs requiring customized support. In contrast to individualized learning, personalised learning emphasizes the notion that learners consider given settings for learning as personally relevant. The personal perspective implies that learners take ownership and responsibility of their learning processes and of the tools which they use. This perspective allows developing courses and services for personalised learning without taking the individual differences of each learner as a starting point. Personalised learning relies on three interrelated theories:

- Constructivism understands learning as the process in which persons actively construct knowledge, concepts, and competences through interacting with their environment [1];

- Reflective thinking stresses that instructional practice should not simply aim at engaging learners at the level of presenting information for understanding and use, but also direct them at meta-levels of learning [2];

- $\quad$ Self-regulated learning focuses on the cognitive and communication processes through which learners control their learning [3]. 
One key concept of self-regulated learning is motivation [4, 5]. Therefore, supporting the learners' motivation is a goal of personalised learning. Motivation rests on three key factors: perceived controllability, perceived value of the learning task and perceived self-efficacy for it $[6,7]$. These aspects depend critically on learners' understanding of their own process of learning and their personal situation in the learning task. Therefore, it is necessary to support the learners' awareness of the learning goals, their progress, and the context in which their learning is situated. Feeding back personal tracked data is a way to enhance the appraisal of these personal dimensions of learning. However, such an approach of autonomous learning support has not retained much attention from research so far. Mining learners' interactions is a common concern of adaptive system improvement. Such systems harness the tracking of various parameters to the production of adaptive presentation, learning paths, content selection [8]. In all cases, the process entails a backstage treatment of personal tracked data but seldom involves presenting it to their owners.

Central to this paper is an analysis of the use of this data for personalising learning experiences and supporting self-regulation in virtual learning environments (VLEs). The analysis is preceded by and grounded in a review of concepts of personalisation coming from education and technology related domains. It is followed by the description of a prototype, developed for the Moodle platform, which starts giving concrete expression to the reconsidered perspective on personalisation outlined here.

\section{Background}

Personalisation of learning has become prominent in the educational field, at various levels: social [9], government policy [10, 11], school management [12, 13] and course/lesson design $[14,15,16]$. Definitions of personalisation greatly vary [17] from the perfectly acceptable but vague "antithesis of impersonal" to the technical and hyper-focused "automatic learning paths structuring to meet the needs of the learner" [18]. The latter view on personalisation is typical of Adaptive Hypermedia Systems [19]. The idea behind Adaptive Hypermedia Systems is the automatic production of educational adjustments based on the learner profile. The breed of personalisation featured in this article is different. It suggests that personalised learning stems from stimulating and supporting learners in self-regulating their learning processes. This has implications for the design of learning environments. It means that learners do not only have access to material to read, websites to explore or assignments and tests to perform, but also to tools for monitoring these activities. From our point of view, personalised learner support based on this approach has a stronger impact on key variables creating ownership and responsibility for the personal learning.

Irrespective to the type of learning, there is only scant research on what makes a student feel that a learning experience is personalised. Waldeck $[20,21]$ undertook such a kind of study in regular face-to-face classrooms. Her study identified factors that students considered meaningful and relevant for characterizing an educative experience as personalised: instructor shares his/her time outside of class, instructor provides counsel to student, instructor exhibits competent communication; instructor cultivates social and personal relationships with students, instructor exhibits 
flexibility with course requirements. The literature surveyed for the present article reveals, in the field of eLearning, no research similar to Waldeck's one. The factors that are contributing to effective personalised learning experiences in the eyes of the students are still to be elucidated. However, they might turn out to be very different from those found by Waldeck. Yet, in Waldeck's approach, the teacher remains central. As self-regulated learning leaves more control to the learner, it is reasonable to consider that the factors influencing the sense of personalisation may be conceptually and theoretically linked to elements enhancing or hampering the controllability of the learning situation. Perceived controllability is, in addition, a key factor of motivation $[6,7]$. The following sections review important dimensions of personalised learning that are in most cases related to control.

\section{Personalised Learning and Control}

Control is a central aspect for personalisation. In virtual learning environments (VLEs) four types of control can be distinguished:

- System control occurs while designing a VLE and is represented by the design decisions of the architects and developers of a VLE. This includes the look and feel of a VLE as well as its functions and the workflows that it enforces;

- Organizational control includes all restrictions, customizations and regulations that are specific to an instance of the VLE. This includes the reflection of the organizational identity as well as the tools and functions that are available to all users of the VLE's instance;

- Teacher control defines the actual educational structure of learning units. This includes the type and availability of learning material, the availability of tools learners can use, as well as the arrangement of these tools that also encompasses their intended usage. This type of control is often called instructional design;

- Learner control reflects the ways through which learners can take control over their learning processes.

As this typology shows, learners' personal initiatives (lowest level of control) do not take place in a vacuum. Formal learning usually occurs thanks to externally prestructured elements combined with a space of possibilities opened up only in the actual moment of learning. Personalised learning does not require that learners have all control over their learning environment, but it requires some control for the learners [22]. This can be as simple as providing explicit, updated and understandable information useful to monitor and analyze one's learning (see section "Tracking for Mirroring").

\section{Dimensions of Personalised Learning}

Several dimensions are interconnected in the notion of personalised learning experiences. These dimensions can be structured as follows:

- Ownership [10]; 
- Participation [23];

- Diversity [24];

- Regulation $[4,25]$;

- Reflection [26, 27].

These dimensions reflect different aspects of control and determine what is possible in the learning process. Personal information can provide contextual beacons and support successful management of these aspects.

\section{Personalised Learning and Personal Information}

Personal information is not only information about the learner. It also comprises contextual information that characterizes the learners' situation. This includes basic learner information (such as name or student number), information resulting from monitoring a learner's activity, achievement of predefined learning goal, etc.Based on the considerations made for context aware systems [28] and context adaptive learning support [29], the control over personal information can be analyzed on the following five levels: data collection, information selection, arrangement, application, presentation. It is suggested that the decisions, the levels of control, and the availability of personal information at these levels influence the learners' control of and commitment to their own learning. In the so called personal learning environments (PLEs) [30, 31, 32], learners are supposed to have full control over their personal information, while in VLEs learners have often limited or no access and control over it. This is particularly the case for tracked information.

\section{Tracking for Mirroring}

Mirroring, i.e displaying tracked interaction footprints to the benefit of learners [33] is not a trivial task. It raises pedagogical, interface-related and technical issues. One of them relates to tracking facilities. User tracking is a key process for user and learner modeling [34] that involves recording user interactions with the intention to store them for further processing. This information is exploited to develop assumptions about the user, to generalize interaction histories into patterns, to classify or cluster these patterns.

Many VLEs create interaction histories as part of their standard functionality. Such monitoring of personal learning actions is usually only accessible to lecturers, tutors, administrators or researchers. Furthermore, the related monitoring functions are often detailed but complex transcripts of the learner activity. Therefore, many approaches exist for better structuring and presentation of this information in order to support teaching staff in controlling the activities in the online environment. An extensive overview of the different approaches is provided by Romero \& al. [35]. There are only a few systems that make tracking information available to learners (see details in the next section). These systems can be a form of navigation support [36]. In this case the student tracking is used to show which competences and course topics have successfully been completed and which topics are still to be learned. These 
educational tools usually require an additional concept and competence model that is tightly coupled with the course material.

Interactions with learning footprints have privacy issues that are frequently raised and discussed in the context of user modeling [37, 38]. These topics are closely related to the control of information. Such concerns should be balanced with benefits for learning that the release of this information might yield.

Prior research has suggested that learners depend on external information on the own activity to analyze, organize, and orientate their actions in complex environments $[4,25]$. Hence, the personal information that is represented in a learner's interaction history might be related to personalised learning experiences. Previous work $[39,40]$ suggests that personal information can serve as feedback that helps learners to reflect on the learning process. Therefore, it can be assumed that information from user tracking supports learners to examine their position in the learning process and to regulate their learning activity. This conceptual claim guides the whole work presented here. In concrete terms, personal tracked data can be harnessed to various instructional purposes that must be analyzed in the specific learning contexts. However, both the abstract and the down-to-earth levels presuppose the availability of personal learning footprints. In order to resolve justified privacy concerns and the need for personalisation it is crucial to understand the structure and organization of personal information across the five levels of personal information control given in the section "Personalised Learning and Control of Personal Information". Table 1 maps these five levels against the architecture for context aware systems that is contributed in [28].

Table 1. Comparison of architectural layers and personalisation levels.

\begin{tabular}{cc}
\hline Architecture layers & Personalisation level \\
\hline 1. Sensor layer & Data collection \\
2. Semantic layer & Information selection \\
3. Control layer & Information arrangement \\
3'. Control layer & Information application \\
4. Indicator layer & Information presentation \\
\hline
\end{tabular}

The levels "arrangement" and "application" are two types of the architecture's control layer. Arrangement refers to the organization of personal information sets from a learner's interaction history. The level "application "describes higher level processing of the personal information. Examples of such higher level processing are recommendation systems or adaptation engines.

\section{Mirroring for Personalising}

The view on personalisation examined in this paper focuses on learner's control. It is asserted that one of its influencing factors is the availability of personal information and the ways that enable the stakeholders of the learning processes to use this information according to their needs. The personal information, properly fed-back to 
the persons they come from, can document their development of knowledge and skills in a learning environment and their course of actions at task level. Viewed in this manner, personalised learning quite often implies the development of different kinds of organizing and presenting information about:

- Situation-related aspects: they concern the fixed components of the learning tasks (targeted learning goals, available learning resources, mandatory and optional tasks, needed and trained skills, time allocations, marks, etc.);

- Self-related aspects: they relate to learning behaviors and achievements and personal learner information in general (teacher's marks and remarks, tasks completed, achieved learning goals, resources consulted, time spent, skills self-assessment, note-taking tools like journals or learning diaries, etc.);

- Social-related aspects: they cover social awareness clues (including comparison processes with data coming from peers or from an expert). As Web 2.0 gains momentum, this social information increases in quantity and availability, inviting to a systematized observation of its potential for promoting self-regulated personalized learning.

Agents depend on this personal and contextual information [4] to organize, orientate and navigate through complex environments. By exerting their understanding on these three sources of information, in order to support decisionmaking for self-regulation, learners personalize their learning.

The design of tools stimulating the appraisal of contextual and personal information is highly dependant on the system's capacity to track interaction footprints and to feed them back to the learner in appropriate presentation modes. This presentation to individual end-users of what the system has captured from their learning episodes is called "mirroring". In the type of personalisation exposed here, tracking tools and techniques are oriented towards this mirroring and receive their value from it. Personalising learning flows therefore partly from an appropriate integration of personal information in the learner's environment. This might sound obvious but a literature review shows it is not. A few articles exhibit interest for learning traces but they usually see learners as indirect benefactors of their treatment. Direct users are systems, instructors or researchers, as detailed now.

\section{Tracked Data for Adaptive Systems}

Adaptive systems make use of mining techniques. Learner is observed through a grid of parameters. Different values for these parameters trigger automatic application of rules leading to the production or adaptation of personal learning paths. The goal remains a background treatment of this data and hardly the mirroring of their actions to students. The principle of presenting tracked traces to learners does not deny the value of research in automatic customization procedures but invites to investigate its possible and desirable complementarities [41] with an approach of personalisation concerned about autonomy development and knowledgeable personalisation. In this respect, several authors, coming from the adaptive learning field itself, recently emphasized the importance of scrutability, namely the explicit communication to students of the pedagogical aspects framing the personalised learning experience designed for them by adaptive learning technology. By stressing upon learners' 
awareness of the automated personalisation process they are committed to, scrutability and inspectable open learner models [42, 43, 44, 45, 46, 47] convey a view on ownership and personalisation close to the one outlined by the present article. Advocating for explanation of system decisions to the learner posits that learning and autonomy development request some sense of control of the learning environment. It also acknowledges the importance to reflect about oneself in a defined learning context.

\section{Tracked Data for Instructors and Researchers}

Some authors expressed interest for the exploitation of different kinds of interaction footprints by researchers [48, 49]. Others speculated about its benefit for instructors [50]. Among them, Nagi \& Suesawaluk [51] recommended tutors to make use of the students data tracked by the Moodle eLearning platform in order to better regulate their courses. With a tool called CourseVis, Mazza \& Dimitrova [52] took student tracking data collected by content management systems and generated graphical representations useful to instructors to gain an understanding of what is happening in distance learning classes. This work lead to the production of Gismo, a tool managing the visualization of data tracked in Moodle [53]. In a similar vein and on the same platform, Zhang et al. [54] developed a VLE log analysis tool, called Moodog, to track students' online learning activities. The goals of Moodog were twofold: first, to provide instructors with insight about how students interact with online course materials, and second, to allow students to easily compare their own progress to others in the class. The latter objective sounded congruent with the approach defined in this article. However the authors eventually postponed its achievement to a subsequent study. Scheuer and Zinn [55] developed an interesting tracking system called the Student Inspector. In their conclusion, they only evoked the possibility to open the tool to students.

The presentation of personal data to learners in a context of self-regulated learning do not preclude a parallel use of user tracking data by instructors. Azevedo's [56] findings show that external regulation using human tutors enhances learning via hypermedia. However increased awareness (making learning an object of attention/reflection) of the learning process obtained, on the learner's side, by mirroring personal information, is desirable as well. It has also the potential to boost the relevance of tutor action.

\section{Tracked Data for Learners}

Attempts to place learning traces in the hands of lifelong learners who therefore turn to be agents and researchers in their own learning processes [3] are not numerous. In addition, they give contrasted results [57]. For instance, in StudyDesk [58] and ACE [59] systems, the use of available personal footprints by the learners appears to remain close to zero. It means that the mere presence of such tools is not enough to improve personalised self-regulated learning, unless students are somehow motivated to use it. Johnson \& Sherlock [60] also observe that self-analytics tools can be 
unwelcome because they represent an incentive to change learning habits, which is hard for many learners. Nevertheless, they conclude that this kind of personal data mirroring amplify conversations about learning, which might be a condition for initiating the self-changing process. But aside from these exploratory studies, the benefits that mirroring interaction with the course might yield for the student is not an object of high attention.

Glahn \& al. have notwithstanding initiated a systematic investigation of the use of personal traces. They analyzed the support of self-directed learning with Web2.0 services $[29,39,40]$. These studies focused on how the presentation of recorded user activity supports reflection and engagement in personal learning. The finding of these studies is that mirroring of personal learning activity depends on two design principles:

- Perspective of learners in their current learning context;

- Contrasting information that allows the learner to evaluate the own actions.

These results suggest that appropriate tooling can support personalization of learning through information that is suitable to reflect on the learning process. One tool, coined by the authors "smart indicators" displays contextualized indicators about achievements, incentives, progress.

\section{Personalisation in Virtual Learning Environments - A Prototype}

Based on the system architecture for context aware systems [28], a prototype for personalisation in virtual learning environments is being developed. This prototype instantiates concepts, concerns, requirements and design principles conveyed by the different view on personalisation elaborated above. It capitalizes on an existing system [29, 39] that adopted an architecture for mirroring learner activity using Web2.0 services. It transfers and expands it to the Moodle platform (http://www.moodle.org). A small-scale online course has been specially designed to embed the prototype and to serve as a playground for further developments and experimental studies. Web usability principles is the topic of this course. It has been designed according to a pedagogical pattern called "Reading - Questions \& Answers - Test" (RQAT) [61]. The prototype, whose first components are presented hereunder, aims to ascertain the technical feasibility and to substantiate the pedagogical value of the approach. A series of studies is planned in order to investigate possible benefits of the mirroring, among them: increased awareness about learning actions and behaviours, training of self-analytic behaviours as a situated learner, enhanced ownership of learning processes, increased sense of personalisation, improved mental model of the learning context [62] and of oneself inside this context. The personalisation of a generic course that the prototype operates takes advantage of the conjunction of tracking, mirroring and visualization. Visualizations have different degrees of complexity and interactivity:

- mirroring visualization presents information about different components of the learning task and learner's actions within. It can be responsive or not, interactive or not; 
- responsive visualization is a visualization that dynamically reacts on user activity;

- interactive visualization is a visualization the learner can act upon.

The prototype mostly concentrates on mirroring responsive visualization.

\section{Moodle}

The prototype provides a modular approach that allows system developers, instructors, and learners, to apply the above described concepts for personalisation. Additionally, it allows stakeholders to hook their preferred information processing tools onto the system. The key function of the prototype is to visualize learning activity, stored in Moodle's activity log, back to the learners. The present prototype has two distinguishing features compared to other activity-visualization plug-ins for Moodle. Firstly, it implements the different levels of personal information processing as independent services. Secondly, it is fully integrated into the Moodle platform. For the prototype three additional requirements were formulated. First, it has to be possible to add new perspectives on personal information. This defines that new ways of information selection can be easily added without much effort. In the terminology of the underlying architecture this means that new aggregation rules for the user tracking can be added at any time. Second, it has to be possible to create new arrangements of the selected information. Finally, a flexible information visualization approach is needed that allows adding new and replace existing visualizations, without concerning the underlying data. This requirement defines that different visualizations can be used of the same personal information as well as that the same visualizations can get used for different types of personal information. The tight integration into the Moodle platform assures that all system functions for authentication and authorization are appropriately applied for the role of the current user. Moreover, it assures that the prototype framework uses the same data as other components of Moodle. This is an advantage compared to the approaches of the systems for visualizing user tracking information for Moodle that have been discussed earlier in this paper. Instead of using a proxy repository for analyzing the learner activity the framework uses Moodle's internal learner tracking and can provide live information on the learning activity. In addition to the shared data, the prototype framework is part of the Moodle system and can therefore use the Moodle interfaces for authentication and authorization of incoming data requests. The four system layers of the architecture are reflected by the framework as following.

The Sensor Layer. The purpose of this layer is to collect and to store traces of actions. These traces can be accesses to a learning resource, writing a forum posting, or the results of a test. Moodle implements a detailed action logging that is automatically integrated into the different plug-ins of the system. Additionally, some Moodle plug-ins allow a more detailed view on the learners' activities. Therefore, it is not necessary to implement a separate sensor layer for tracking learner actions in Moodle. 
The Semantic Layer. This layer processes the data collected by the sensor layer into semantically meaningful information. At the level of the semantic layer several aggregation rules can be active to process the traces of learning activity. The current system implements the sensor layer as a REST service through which the different aggregation rules have unique names and can be directly accessed through an URL. At this stage each aggregation rule of the semantic layer represents an SQL statement that processes Moodle's user tracking. Each aggregation rule returns the result data to the JSON format that can be easily interpreted by web-frontends. XML output of the data is planned for future releases. Each aggregation rule can be limited to different social contexts of the learner and to a specific course. So far the social context self, course fellows and contacts are implemented. The context "self" includes only the data of the learner who is currently logged in while accessing the Moodle system. The context "course fellows" includes the data of all other learners who are enrolled in the same courses as the learner. The context "collaborators" includes all learners who were directly collaborating with the learner in at least one of the different collaboration tools of Moodle.

The Control Layer. This layer defines the arrangement of the aggregators and the visualization that are used for mirroring. The control layer is implemented as a plugin that provides several widgets that can be independently integrated into the user interface of a course. Each widget contains a set of aggregators and visualizations, which can be configured by the instructor of a course.

The Indicator Layer. This layer provides different presentation modes for the data of the semantic layer. The indicator chooses the presentation mode based on the configuration of the indicator layer and receives the data from the semantic layer. The indicator layer is embedded into the user interface of Moodle through a JavaScript module. It fetches the data from the semantic layer through service requests.

\section{Personal Information Management}

The aggregation rules of the semantic layer of the framework offer direct support for the design principle of contrast. This principle states that visualized information is easier understood if it is presented in the context of comparable information. In other words, the other information contrasts the presented information and highlights its specific qualities. The contrasting information can be considered as a reference that allows to assess the presented information and to relate it to mental concepts of the context in which the learning takes place. The present prototype of the framework supports two types of contrasting information: yardstick references and social context references. A yardstick reference provides information on goal achievement. A yardstick reference is a value that provides a contextual reference for the presented personal information. The current activity of a learner can then be described as a percentage of the yardstick reference. A yardstick reference is typically defined in the arrangement of the aggregators and presentation modes. In the present framework two types of yardsticks are supported: predefined yardsticks that are defined at design 
time of a course, and dynamic yardsticks that use a different aggregation rule to determine the yardstick from the current activity. An example of a dynamic yardstick can be found in Glahn \& al. [29]. The second type of contrasting information is given by social context references. These references can be applied as special filters on the aggregation rule. Such filter can cause an aggregation rule to return the average activity of a learner's peers instead of the activity of the learner. For Moodle four relevant social contexts were identified: group members, contacts, course fellows, peers. Contrasting information shows that contextual information is considered as part of the personal information that can get controlled by the learner. In Figure 1, two pieces of personal information are visualized: the total time spent on the course (box 1) by the learner and the number of learning actions he performed (box 2). The mirrored information about the total time is simply retroacted to the learner. The mirrored information about the number of learning actions is enriched through a comparative setup which also mirrors the number of actions by the peers. Another yardstick could be a number of actions suggested by the teacher.

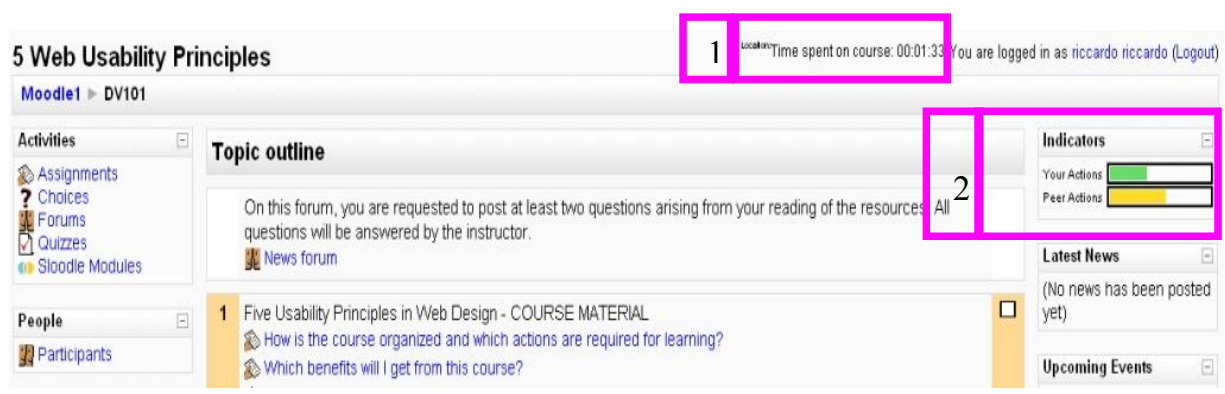

Figure 1. The Moodle interface mashes up information centered on the course and information about the personal experience of the course by the learner (Time spent on course $\{$ box 1$\}$, Student's actions compared to peers' actions $\{$ box 2$\}$ )

\section{Validation of the Approach}

This research emphasizes interaction traces in order to inspect to what extent their feedback to the learner can be beneficial to him and to the design of his learning environment. Main benefits from this personal history of learning begins with the mirroring of personal information. Sometimes or with some learners, contemplating it will be enough to generate some kind of diagnosis (for instance: "the assignment requests from me that I post 12 messages in the forum and I have only 3 so far") and to self-administer appropriate remedial. But in other occasions, the way to achieve the improvement will not be so straightforwardly inferred from mirroring even if it brings valuable information (for instance: "Compared to the number of learning activities performed by my peers, I am slower"). It means that students must be prepared to interpret their personal data and, in some cases, must receive help for this. An underpinning hypothesis for this approach is that making learning processes explicit and comparable, through their mirroring, can affect student attributions of learning (locus of control) and increase what is advocated by all promoters of lifelong 
learning: the responsibility and ownership of one's own learning. Tracking might be related to self-efficacy aspects. A number of studies indicate that high-mastery students are more successful overall because they persevere, experience less anxiety, use more strategies, and attribute their success to controllable causes. It means that the others could benefit from an explicit, reified view of their actions and realize they are in control. Additionally, it is hypothesized that the provision of personal info can play the role of an involvement factor.

\section{Conclusion}

This paper delineated and documented a perspective on personalisation based on the mirroring of personal tracked data. This approach advises to not merely use personal tracked data for backstage adaptation but to mirror it back to the learner. It therefore entails the availability of tools that automatically collect and aggregate selected information on the personal learning activities and interactions and make it visible to the user. In its last part, the article contributed a prototype which instantiates concepts, concerns, requirements and design principles conveyed by this different view on personalisation. Further elaboration of the prototype as well as experimental settings meant to substantiate the pedagogical value and possible benefits of the approach are on their way.

Acknowledgements. This paper is sponsored by the TENCompetence project (www.tencompetence.org), funded by the European Commission's 6th Framework Programme and by the GRAPPLE (www.grapple-project.org) project funded by the European Commission's 7th Framework Programme.

\section{References}

1. Terhart, E.: Constructivism and teaching: a new paradigm in general didactics? Journal of Curriculum Studies 35, 1, 25--44 (2003)

2. Ertmer, P. A., Newby, T. J.: The expert learner: Strategic, self-regulated, and reflective. Instructional Science 24, 1, 1--24 (1996)

3. Winne, P.: A Perspective on State-of-the-art Research on Self-regulated Learning. Instructional Science 33, 5-6, 559--565 (2005)

4. Butler, D. L., Winne, P. H.: Feedback and self-regulated learning: a theoretical synthesis. Review of Educational Research 65, 3, 245--281 (1995)

5. Ley, K., Young, D. B.: Instructional principles for self-regulation. Educational Technology Research and Development 49, 2, 93--103 (2001)

6. Ryan, R. M., Deci, E. L.: Self-determination theory and the facilitation of intrinsic motivation, social development, and well-being. American Psychologist, 68--78 (2000)

7. Viau, R.: La motivation : condition au plaisir d'apprendre et d'enseigner en contexte scolaire. In 3e congrès des chercheurs en Éducation, Brussels, Belgium (2004)

8. Brusilovsky, P.: Adaptive Hypermedia. User Modeling and User-Adapted InteractionIn: User Modeling and User-Adapted Interaction 11, 1-2, 87--110 (2001) 
9. Bonal, X., Rambla, X.: The Recontextualisation Process of Educational Diversity: new forms to legitimise pedagogic practice. International Studies in Sociology of Education 9, 2, 195--214 (1999)

10. DfES: A National Conversation about Personalised Learning, http://www.standards.dfes.gov.uk/personalisedlearning/downloads/personalisedlearni ng.pdf (2004)

11. Leadbeater, C: Pamphlet - Learning About Personalisation, $\mathrm{http}: / / \mathrm{www} \cdot$ demos.co.uk/publications//learningaboutpersonalisation (2004)

12. Lambert, M. B., Lowry, L. K.: Knowing and being known: Personalisation as a foundation for student learning. Small Schools Project, Seattle (2004)

13. West-Burnham, J., Coates, M.: Personalising learning : transforming education for every child. Network Educational Press, Stafford, UK (2005)

14. Martinez, M.: Designing learning objects to personalize learning. In D.A. Wiley (ed.): The Instructional Use of Learning Objects. Agency for Instructional Technology, Bloomington, pp. 151--173 (2002)

15. Polhemus, L., Danchak, M., Swan, K.: Personalised Course Development Techniques for Improving Online Student Performance. In: Conference of Instructional Technologies (CIT). Stonybrook, New York (2004)

16. Tomlinson, C. A.: Mapping a route toward differentiated instruction. Educational Leadership 57, 1, 12--16 (1999)

17. Noss, R.: Foreword. In: Magoulas, G., Chen, S. (eds.) Advances in Web-based Education: Personalised Learning Environments. Information Science Publishing (2006)

18. Schmoller, S.: FE White Paper - the personalisation virus is spreading, http://fm.schmoller.net/2006/04/fe_white_paper_html (2006)

19. Primus, N. J. C. A generic framework for evaluating Adaptive Educational Hypermedia authoring systems - Evaluating MOT, AHA! and WHURLE to recommend on the development of AEH authoring systems, doctoral dissertation. University of Twente, Twente (2005)

20. Waldeck, J. H.: What Does "Personalised Education" Mean for Faculty, and How Should It Serve Our Students? Communication Education 55, 3, 345--352 (2006)

21. Waldeck, J. H.: Answering the Question: Student Perceptions of Personalised Education and the Construct's Relationship to Learning Outcomes. Communication Education 56, 4, 409--432 (2007)

22. Dron, J.: Controlling learning. In: Kinshuk, Koper R., Kommers, P., Kirschner, P., Sampson, D.G., Didderen, W. (eds.) In: 6th IEEE International Conference on Advanced Learning Technologies, pp. 1131--1132. IEEE The Computer Society Los Alamitos, Washington, Tokio (2006)

23. Lave, J. and Wenger, E.: Situated learning. Legitimate peripheral participation. Cambridge: Cambridge University Press (1991)

24. Wilson, S., Liber, O., Johnson, M., Beauvoir, P., Sharples, P., \& Milligan, C.: Personal Learning Environments: Challenging the Dominant Design of Educational Systems. In E. Tomadaki \& P. Scott (eds.) Proceedings of the workshop Innovative Approaches for Learning and Knowledge Sharing at the EC-TEL 2006, pp. 173-182 (2006)

25. Garries, R., Ahlers, R., Driskel, J.E.: Games, motivation, and learning: a research and practice model. Simulation \& Gaming 33, 441--467 (2002)

26. Attwell, G., Chrzaszcz, A., Hilzensauer, W., Hornung-Prahauser, V., \& Pallister, J.: Grab your future with an e-portfolio - Study on new qualifications and skills needed by teachers and career counsellors to empower young learners with the e-portfolio concept and tools. MOSEP Summary Report, http://www.mosep.org/study (2007) 
27. Schön, D.A.: The Reflective Practitioner: How Professionals think in Action. Maurice Temple Smith, London (1983)

28. Zimmermann, A., Specht, M., Lorenz, A.: Personalisation and context management. User Modeling and User-Adapted Interaction 15, 3-4, 275--302 (2005)

29. Glahn, C., Specht, M., Koper, R.: Smart indicators on learning interactions. In: E. Duval, R. Klamma, M. Wolpers (eds.) Creating new learning experiences on a global scale. LNCS, vol. 4753, pp. 56--70. Springer, Berlin, Heidelberg (2007)

30. Agustiawan, M.: PLEF: a conceptual framework for Personal Learning Environments, dissertation. Rheinisch-Westfalische Technische Hochschule Aachen (2008)

31. Anggraeni: PLEM: A Web 2.0 Driven Service for Personal Learning Management, dissertation. Rheinisch-Westfalische Technische Hochschule Aachen (2008)

32. Moedritscher, F.,Wild, F.: Why not Empowering Knowledge Workers and Lifelong Learners to Develop their own Environments? In 9th International Conference on Knowledge Management and Knowledge Technologies (I-KNOW), Graz, Austria (2009)

33. Jermann, P., Soller, A., Mühlenbrock, M.: From mirroring to guiding: A review of the state of art technology for supporting collaborative learning. Euro-CSCL, 324-$331(2001)$

34. Kobsa, A.: Generic User Modeling Systems. In P. Brusilovsky, A. Kobsa, W. Nejdl, (eds.): The Adaptive Web: Methods and Strategies of Web Personalisation. Berlin, Heidelberg, New York: Springer Verlag, 136--154 (2007)

35. Romero, C., Ventura, S., García, E.: Data mining in course management systems: Moodle case study and tutorial. In Computers \& Education 51, pp. 368--384 (2008)

36. Dieberger, A.: Supporting social navigation on the world wide web. International Journal of Human-Computer Studies, 46, 805--825 (1997)

37. Kobsa, A.: Tailoring privacy to users' needs. In M. Bauer, P. J. Gmytrasiewicz and J. Vassileva, eds.: User Modeling 2001: 8thInternational Conference. Berlin Heidelberg: Springer Verlag, 303--313 (2001)

38. Schreck, J.: Security and privacy in user modeling. Dissertation. FB. Mathematik \& Informatik, Gesamthochschule Essen, Germany (2001).

39. Glahn, C., Specht, M., Koper, R.: Reflecting on web-readings with tag clouds. In: 11th International Conference on Interactive Computer aided Learning (ICL), Villach, Austria (2008)

40. Glahn, C., Specht, M., Koper, R.: Visualization of interaction footprints for engagement and motivation in online communities. Journal for Educational Technology and Society (2009) (in press)

41. Verpoorten, D.: Adaptivity and adaptation: which possible and desirable complementarities in a learning personalisation process? Policy futures in education (2009) (in press)

42. Ahn, J., Brusilovsky, P., Grady, J., He, D., Syn, S. Y.: Open user profiles for adaptive news systems: help or harm? In 16th International World Wide Web Conference (WWW 2007), Banff, Canada (2007)

43. Bull, S., Nghiem, T.: Helping Learners to Understand Themselves with a Learner Model Open to Students, Peers and Instructors. In: International Conference on Intelligent Tutoring Systems 2002 - Workshop on Individual and Group Modeling Methods that Help Learners Understand Themselves, San Sebastian, Spain (2002)

44. Czarkowski, M., Kay, J.: How to give the user a sense of control over the personalisation of adaptive hypertext? In: Workshop on Adaptive Hypermedia and Adaptive Web-Based Systems - User Modeling Session, pp. 121--133. Budapest, Hungary, http://wwwis.win.tue.nl/ah2003/proceedings (2003) 
45. Kay, J.: Learner Know Thyself: Student Models to Give Learner Control and Responsibility. In: Halim, Z., Ottmann, T., Razak, Z. (eds.), International Conference on Computers in Education ICCE'97, pp. 18--26. AACE: Charlottesville (1997)

46. Kay, J.: An exploration of scrutability of the user models in personalised system. Engineering Personalised Systems (2002)

47. Zapata-Rivera, J. D., Greer, J. E.: Externalising Learner Modelling Representations. In Workshop on External Representations in AIED at the International Conference on AI and Education (AIED'2001), San Antonio, Texas (2001)

48. Leclercq, D., Fernandez, A., Prendez, M. P.: OLAFO, Hypermédia destiné à entraîner à l'apprentissage de l'espagnol écrit. STE, Liège (1992).

49. Perry, N. E., \& Winne, P. H.: Learning from learning kits: gStudy traces of students' self-regulated engagements using software. Educational Psychology Review, 18, 211-228 (2006).

50. Diagne, F.: Instrumentation de la supervision de l'apprentissage par la réutilisation d'indicateurs: Modèles et Architecture, dissertation. Université Joseph Fourier Grenoble (2009)

51. Nagi, K., Suesawaluk, P.: Research analysis of Moodle reports to gauge the level of interactivity in elearning courses at Assumption University, Thailand. In: International Conference on Computer and Communication Engineering, Kuala Lumpur (2008)

52. Mazza, R., Dimitrova, V.: Visualizing student tracking data to support instructors in web-based distance education. In: 13th International World Wide Web Conference (WWW 2004) - Educational Track. New York (2004)

53. Mazza, R., Botturi, L.: Monitoring an Online Course With the GISMO Tool: A Case Study. Journal of Interactive Learning Research, 18, 2, 251--265 (2007)

54. Zhang, H., Almeroth, K., Knight, A., Bulger, M., Mayer, R.: Moodog: Tracking Students' Online Learning Activities. In ED-MEDIA, Vancouver (2007)

55. Scheuer, O., Zinn, K.: How did the e-learning session go? - The Student Inspector. In 13th International Conference on Artificial Intelligence in Education (AIED'07), Los Angeles (2007)

56. Azevedo, R.: Computer Environments as Metacognitive Tools for Enhancing Learning. Educational Psychologist 40, 4, 193--197 (2005)

57. Perrenoud, P.: Le désir de ne pas savoir - Ambivalences et résistances face à la posture réflexive. In: Troisième journée pédagogique de l'IFRES "Innovations pédagogiques dans les pratiques réflexives", Liège, Belgium (2009)

58. Narciss, S., Proske, A., Koerndle, H.: Promoting self-regulated learning in web-based learning environments. Computers in Human Behavior 23, 1126--1144): Elsevier Science Publishers B. V. (2007)

59. Specht, M., Oppermann, R.: ACE - adaptive courseware environment. The New Review of Hypermedia and Multimedia, 4 - Special Issue on Adaptivity and user modeling in hypermedia systems 1, 141--161 (1998)

60. Johnson, M., Sherlock, D.: Personal Transparency and self-analytic tools for online Habits. In: TENCompetence Workshop Stimulating Personal Development and Knowledge Sharing, Sofia, Bulgaria (2008)

61. Verpoorten, D., Poumay, M., Delcomminette, S., Leclercq, D. From Expository Teaching to First e-Learning Course Production: Capture in a 17 Online Course Sample of a Pedagogical Pattern Facilitating Transition. In 6th IEEE International Conference on Advanced Learning Technologies (ICALT 2006), Kerkrade, The Netherlands (2006)

62. Seel, N. M.: Epistemology, situated cognition, and mental models: 'Like a bridge over troubled water'. Instructional Science 29, 4, 403--427 (2001) 